\title{
ANTERIOR MEDIASTINOTOMI
}

\author{
Oya YILDIZ, Elif DUMAN, Ayten Kayı CANGIR
}

Ankara Üniversitesi Tıp Fakültesi, Göğüs Cerrahisi Anabilim Dalı, Ankara, Türkiye

e-posta: Ayten.K.Cangir@medicine.ankara.edu.tr

doi:10.5152/tcb.2011.10

Akciğer kanserinde mediastinal lenf bezi evrelemesi tanı ve tedavinin planlanmasında temeldir. Anterior mediastinotomi, akciğer kanserinin tanısında, mediastinal evrelemesinde ve anterior mediastinal kitlelerin tanısal biyopsisinde kullanılan minimal invaziv bir cerrahi girişimdir (1).

Anterior mediastinal yerleşimli tümörler germ hücreli tümörler; timomalar, timik karsinomlar ve malign lenfomalar gibi farklı hücre tipinde varyasyonlar göstermektedir. Son dönemde bu tümörlerde kemoterapi ve radyoterapi içeren kombine tedaviler ile sağ kalım oranları artmıştır. Mediastinal kitlelerin bilgisayarlı tomografi ve ultrason eşliğinde perkütan iğne biyopsisi yapılmaktadır, ancak bu örneklemeler ile doğru terapötik planı yapmak için tümör tipi uygun histolojik tanıyı sağlamayabilir (2).

Charlen, 1959 yılında akciğer kanserinde servikal mediastinoskopiyi tanımlamıştır. Servikal mediastinoskopi ile paratrakeal ve subkarinal lenf bezlerine ulaşılabilmesine karşın paraaortik ve subaortik lenf bezleri örneklenemez (3). Chamberlain, Stenner, Calvin ve Chander tarafından 1966 'da tanımlanan anterior ya da parasternal mediastinotomi ile hem akciğer kanserinin mediastinal lenf bezi evrelemesinde paraaortik ve subaortik lenf bezlerinin örneklenmesi hem de mediastinal tümörlerden tanısal biyopsi alınması sorunu aşılmıştır (4). Anterior mediastinotomi, para ve subaortik mediastinal lenf bezlerine metastaz en sık olduğu için genellikle bu tümörlerin mediastinal lenf bezi evrelemesinde kullanılır ve sensitivitesi \%63-86, spesifitesi \%100'dür (5-8). Bunun yanı sıra sağ tarafta da kullanılabilir ve her iki tarafta hilus, akciğer ve plevraya ulaşımı sağlayabilir. Anterior mediastinotomi ile sağda 4 ve 10 no.lu lenf bezlerinden biyopsi alınabilirken; solda arkus aorta nedeniyle ulaşılamaz. Anterior mediastinotomi ile; 1) rezektabilite saptanabilir, 2) tanı konulur ve 3) torakotomi öncesi hastanın performansını bozmaz. Avantajları; anterior, üst akciğer hiler yapılara ve mediastinuma bilateral kolay erişimdir. İnsizyon istenirse anterior torakotomi olarak genişletilebilir. Dezavantajları ise sınırlı görüş, posterior hiler yapıların kısıtlı görünümü, internal mammarian damarların bağlanma intimali ve anteriorda bulunan sınırlı yumuşak doku nedeniyle yara iyileşmesi problemleridir (9-11).

Akciğer kanseri tanısı ve evrelemesinin dışında anterior mediastinotomi anterior mediastinal kitlelerin biopsisinde de kullanılabilir (Resim 1). Anterior mediastinoskopi terimi, kostal kartilajın kaldırımadığı ve mediastinoskopun ikinci interkostal aralıktan yapılan küçük bir insizyondan geçirildiği orjinal operasyonun sık yapılan bir modifikasyonunu tanımlamaktadır (1).

\section{Endikasyonları}

Anterior mediastinal kitleler ve sol üst lob kanserleri anterior mediastinostominin en sık endikasyonlarıdır (2). Literatürlerde de belirtildiği gibi anterior mediastinostomi endoskopi ve skalen lenf nodu biopsisi gibi minör cerrahi girişimlerle eksploratris torakotomi arasındaki geniş tanısal işlem boşluğunu doldurmaktadır (2).

Anterior mediastinal kitle tanısında bilgisayarlı tomografi ve ultrason eşliğinde biyopsi kullanılabilir, ancak bu biyopsiler ile çoğu lenfoma ve germ hücreli 
tümörlerin alt tipleri tanımlanamamaktadır (Resim 2). Tanısal intimallerin çeşitliliği nedeniyle anterior mediasten yerleşimli tümörlerde geniş örneklemelere intiyaç vardır. İnvaziv timomalar, germ hücreli tümörler veya malign lenfomalar gibi anterior mediastinal yerleşimli malign tümörlerde kombine tedaviler sağ kalım oranını artırmaktadır. Bu kombine tedavilerden önce histolojik tanının kesinleştirilmesi gerekmektedir. İğne biyopsisi ile alınan örneklerde doku hacmi malign lenfoma, küçük hücreli akciğer kanseri, lenfosit pre-dominant timoma ve karsinoid tümör arasındaki farkı ayırt etmeye sıklıkla yetersizdir. Ayrıca lenfoma ve germ hücreli tümörlerin alt tipi tedaviye karar vermek için immün histokimyasal tekniklerle araştırımalıdır. Malign germ hücreli tümörler iğne biyopsisi örneklerinde görülemeyecek kadar çok komponent içerir. Bu nedenlerle anterior mediasten yerleşimli malign tümörlerde anterior mediastinotomi ile geniş örneklemeler yapılarak tanı kesinleştirilmelidir (12).

Aortopulmoner pencere lenf bezleri sol üst lobun ilk drenaj noktasını oluşturmasına karşın N2 lenf bezi olarak sınıflandırımaktadır. Sol üst lob drenajı sadece komşu subaortik ve anterior mediastinal noktalara değil ayrıca ipsilateral paratrakeal nodlara da olmaktadır. Sol üst lob kanserli çok sayıda hastada bu; sonraki grup metastazları olmaktadır ki diğer N2 olguları gibi çok kötü cerrahi prognozla ilişkilidir (13). Buna karşın, fikse olmayan ya da geniş hacimli olmayan lenfadenopatili, subaortik seviyeyle sınırlı sol üst lob kanserleri \%20-30 5 yıllık sağkalım oranlarına sahiptir. Bu bulgular sol üst lob tümörleriyle ilişkili 5 no.lu lenf bezi biyopsisinin rutinde gerekli olmadığını ancak BT taramada minimal lenfadenopatiden büyükse uygulanabileceğini düşündürmektedir. Anterior mediastinotomi şüpheli sol üst lob tümörü olan hastalarda \%3.4 oranında engellenebilir torakotomi oranlarıyla ve hastaların \%67'sinde bir ya da daha fazla nodal avantaj sağladığı da bildirilmiştir. Schreinemakers ve Bowen yaptıkları çalışmada mediastinoskopi ile lenf nodu metastazı saptanmayan olgularda anterior mediastinotomi ile \%22.6 ve \%36 oranlarında lenf nodu metastazı saptamışlardır (14). Servikal mediastinoskopi ile sağ ya da sol lenf bezlerinde metastatik sonuç elde edilmişse anterior mediastenin örneklenmesine gerek yoktur. Minimal invaziv lobektomi çağında, videotorakoskop ile anteroposterior pencere nodları biyopsisi rezeksiyonun hemen öncesinde mediastinotominin yerini alabilir (15).

Nodal evrelemenin yanısıra, anterior mediastinotomi mediasten, pulmoner damarlar ve frenik sinir invazyonunun değerlendirilebilmesine de olanak sağlar.
Anterior mediastinotomi, anterior mediastinal kitlelerin biyopsisinde de kullanılabilir. Bu kitleler timomaları, timik karsinomaları, germ hücreli tümörleri, lenfomaları, nörojenik tümörleri, perikardiyal kistleri, tüberkülozu, fungal hastalıkları, sarkoidozu, tiroid ve paratiroid bezleri kökenli tümörleri içermektedir (4).

\section{Kontrendikasyonlar ve Dikkat Edilmesi \\ Gereken Durumlar}

Anamnezde sternotomi öyküsü mutlak kontrendikasyon değildir; ancak dikkat edilmesi gerekir. Ancak, anterior mediastinostomi patent sol internal mammarian arter bypass grefti varlığında uygulanmamalıdır. Tekrarlayan sternotomi durumunda kalp cerrahları grefti korumak adına sıklıkla plevrayı açmakta ve onu laterale almaktadırlar. Bunun sonucunda arter akciğer hilumu önüne gelmekte özellikle de frenik sinir seyri düşünüldüğünde yaralanmaya açık hale getirmektedir. Hasar görebilecek diğer yapılar ise vagal sinir, interkostal arter ve ven, superior pulmoner ven, ana pulmoner arter ve aortadır (1).

\section{YÖNTEM}

Hasta supin pozisyonunda ve genel anestezi altındadır. Özellikle hilus, akciğer ya da plevra değerlendirmesi gerekliyse çift lümenli endotrakeal tüp yoluyla seçici akciğer ventilasyonu şart değildir ancak faydalı olabilir. Anterior mediastinoskopi lokal anestezi ile de uygulanabilir. Bu yaklaşım, özellikle genel anestezi uygulandığında ve supin pozisyonunda havayolu kompresyonuna neden olabilecek geniş mediastinal kitleli olgularda faydalı olabilir. Klasik yöntemde, ikinci ya da üçüncü kostal seviyelerde sternal çentiğin $1 \mathrm{~cm}$ lateralinden $6 \mathrm{~cm}$ 'lik transvers insizyon yapılır.

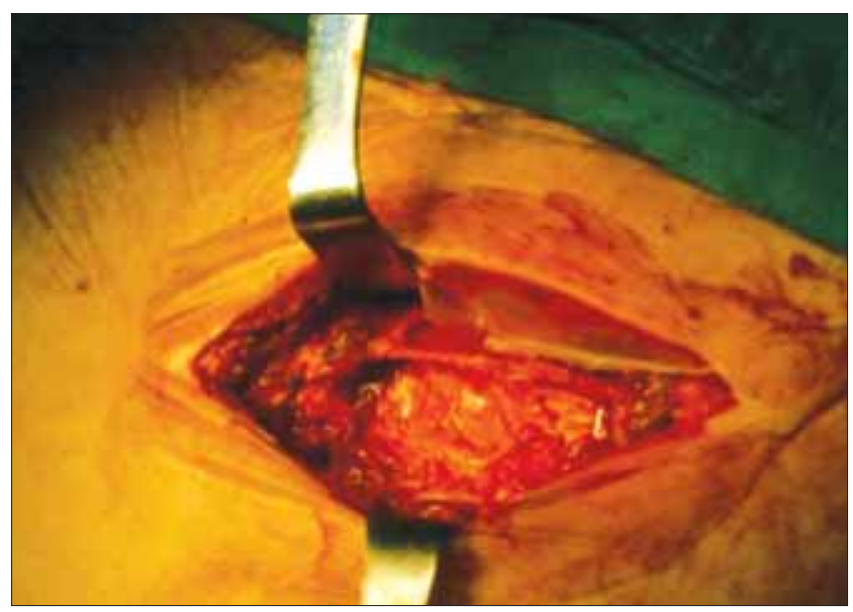

Resim 1.Anterior mediastinotomi intraoperatif görünümü (AÜTF Göğüs Cerrahisi Anabilim Dalı arşivinden) 


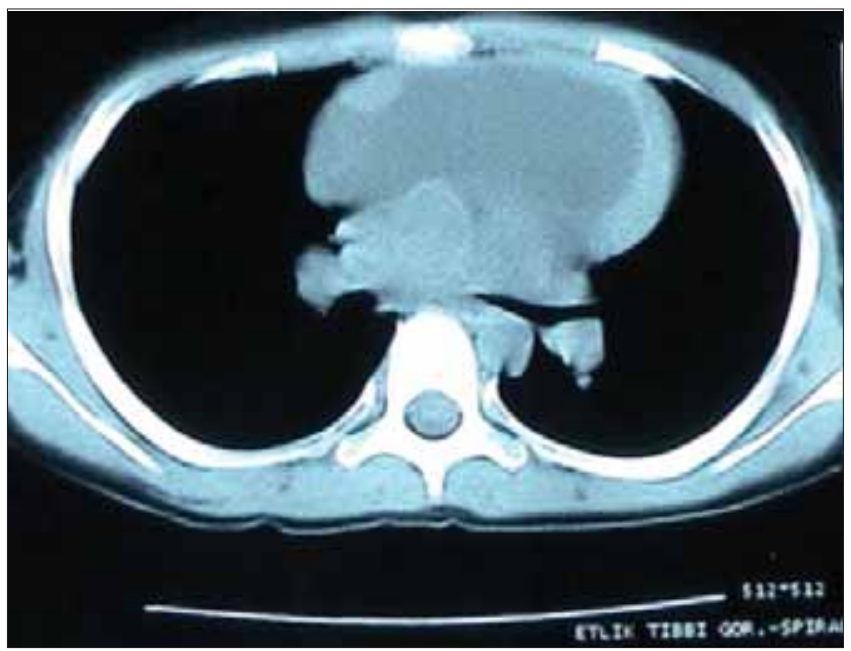

Resim 2. Tanı amaçlı anterior mediastinotomi endikasyonu olan unrezektabl anterior mediastinal kitle

(AÜTF Göğüs Cerrahisi Anabilim Dalı arşivinden)

Pektoralis major kasının lifleri insizyon seviyesinde diseke edilir. Pektoral kas sternokondralden kostakondral bileşkeye rezeke edilen kıkırdağı bölmektedir ve mediasten ise daha sonra posterior perikondriuma doğru devam etmektedir. Çoğu olguda kartilajı çıkarmadan interkostal aralık yoluyla yeterli açıklık sağlanmaktadır. İnternal mammarian arter ve ven retrakte edilebilir, nadiren bağlanması gerekebilir. Mediastinal plevral refleksiyon sternum arka kısmından net bir şekilde görülür ve laterale retrakte edilir. Parmak disseksiyonu gevşek gözeli dokuyu açmakta ve içeriye doğru aorta, pulmoner arter ve müdahale alanını genişletmekte yararlıdır. Sağ mediastinoskopide timusun sağından, asenden aorta, vena kava superior, frenik sinir, superior pulmoner ven, pulmoner arter dalları ve ana bronş görülebilir. Bu alan fiksasyon, invazyon ve lenfadenopati açısından değerlendirilir. Mediastinoskopide olduğu gibi palpasyon sırasında cerrah normal ve anormal yapıların taktil bir haritasını oluşturmakta ve büyümüş nodları serbestleştirebilir. Direkt gözlem ve mediastinoskop kullanımı anatomiyi doğrulamaktadır. Vagal ve frenik sinirler bazen arkus aorta boyunca izlenebilmekte ve rekürren laringeal dal lokasyonu gözlenebilmektedir (1).

Büyümüş lenf bezleri, doğrudan ya da servikal mediastinoskopi için tanımlandığı şekilde diseksiyon, biyopsi ve hemostaz teknikleri kullanılarak örneklenebilir. Anatomik değerlendirme bazen plevrayı açarak ve alanı hem mediastinal hem de plevral yönlerden gözlemleyerek yapılabilir. Bazıları tüm olgularda plevrayı açmayı ve plevral kısımdan biyopsi uygulamayı tercih etmektedir. Eğer mediastinotomi, servikal mediasti- noskopiyle beraber yapılacaksa, aortapulmoner bölgenin iki parmakla palpasyonuna izin verecek şekilde boyun insizyonu açık bırakılmalıdır. Drenaj genellikle gerekli değildir. Eğer plevraya girilmişse yaranın köşesinden küçük bir tüp konulmalıdır. Kapattıktan sonra, tüpün çekilmesiyle beraber akciğerleri $30-40 \mathrm{~cm} \mathrm{H}_{2} \mathrm{O}$ basınçla şişirerek plevral hava alınmalıdır. Eğer akciğer biyopsisi operasyon sırasında yapılıyorsa, tüp yerinde bırakılmalı ve su altı drenaj sistemine bağlanmalıdır (1).

Video yardımlı mediastinostomi tekniği güvenli ve ergonomik kullanıma sahiptir ve son zamanlarda kullanılmaya başlanmıştır. Videomediastinotomi sayesinde büyütme ile daha iyi bir görüntü sağlanır. Videomediastinotomi ile;

1. Chamberline insizyonu minimale indirilmiştir.

2. Ekstraplevral diseksiyon güvenli ve kolaydır.

3. Kostal kıkırdak rezeksiyonu gerekmez.

4. Aortopulmoner pencere nodlarına iyi geçiş olanağı sağlar.

5. Eğitim aracıdır.

\section{Komplikasyonlar}

Anterior mediastinotomi ya da mediastinoskopi servikal mediastinoskopiden çok daha az yapılmaktadır. Komplikasyon oranı servikal mediastinoskopiye göre daha azdır. Mortalite çok enderdir, 151 hastalık retrospektif bir seride mortalite olmaksızın \%6.8 komplikasyon oranları bildirilmiştir (8). Aorta, pulmoner arter ya da superior pulmoner ven hasarıly şiddetli kanama olabilir. İnternal mamiller damarlardan kanama daha sıktır ve daha kolay kontrol altına alınabilir. Diafram paralizisi ve ses kısıklığı frenik ya da rekürren laringeal sinir hasarıyla nadiren oluşabilir. Pnömotoraks sıklıkla gözlenebilir. İnsizyondan tümör ekilmesi nadirdir. Mediastinotomi sonrası şilotoraks nadir de olsa meydana gelebilir $(16,17)$.

Anterior mediastinostomi, eski bir tanısal yöntem olmakla birlikte anterior mediastinal kitlerin tanısında ve aortikopulmoner-paraaortik büyümüş lenf nodları olan akciğer kanserli hastaların evrelenmesinde hala güncelliğini koruyan bir yöntemdir.

\section{KAYNAKLAR}

1. Ahmad US, Blum MG. Invasive diagnostic procedures. In Shields TW, Locicero III J, Reed CE, Feins RH, ed. General Thoracic Surgery, vol 1, 7th ed. Philadelphia: Lippincott Williams and Wilkins; 2009: 301-12.

2. Erino A. Rendina, Venuta F, Giacomo T, Ciccone AM, Moretti MS, Coloni F. Biopsy of anterior mediastinal masses under local anesthesia. Ann Thorac Surg 2002; 74: 1720-3. 
3. Kadokura M, Colby TV, Myers JL. et al. Pathologic comparison of video-assisted thoracic surgical lung biopsy with traditional open lung biopsy. J Thorac Cardiovasc Surg 1995; 109: 494-8.

4. Evans DS, Hall JH, Harrison GK. Anterior mediastinotomy. Thorax 1973; 28: 444-7.

5. Toloza Enn, Harpole L, Detterbeck F, McCrocy DC. Invasive staging of non-small cell lung cancer $A$ review of the current evidence Chest 2003, 123: 157S-66S. [CrossRef]

6. Silvestri GA. Diagnosis and staging of lung cancer. In Shields TW LoCicero III J, Ponn RB, eds. General thoracic surgery. 6th ed. Philadelphia: Lippincott Williams and Wilkins; 2005; 1534-47.

7. Sihoe AD, Yirm AP. Lung cancer staging J Surg Res 2004; 117: 92-106. [CrossRef]

8. Lee JD, Ginsberg RJ. Lung cancer staging: The value of ipsilateral scalene lymph node biopsy performed at mediastinoscopy. Ann Thorac Surg 1996; 62: 338-41 [CrossRef]

9. Nakanishi R, Osaki T, Nakanishi K. et al. Treatment strategy for patients with surgically discovered N2 stage IIIA nonsmall cell lung cancer. Ann Thorac Surg. 1997; 64: 342-8. [CrossRef]

10. Nechala P, Graham AJ, McFadden SD, Grondin SC, Gelfand $G$. Retrospective analysis of the clinical performance of anterior mediastinotomy. Ann Thorac Surg 2006; 82: 2004-9. [CrossRef]
11. Petterson GA, Piazza D, Pearson FG, Todd TR, et al. significance of metasatic disease in subaortic lymph nodes. Ann Thorac Surg 1987; 43: 155-9.

12. Watanabe M, Takagi $\mathrm{K}$, Aoki T et al. A comparison of biopsy through a parasternal anterior mediastinotomy under local anesthesia and percutaneous needle biopsy for malignant anterior mediastinal tumors. Jpn J Surg 1998; 28: 1022-6. [CrossRef]

13. Detterbeck FC, Malcolm M, DeCamp, Jr, Leslie J, Kohman, Gerard A. Invasive Staging* : The Guidelines Chest 2003; 123: 167-75.

14. Schreinemakers $\mathrm{HH}$, Joosten HJ, Mravunac M, Lacquet LK. Parasternal mediastinoscopy. Assessment of operability in left upper lobe lung cancer: a prospective analysis. J Thorac Cardiovasc Surg 1888; 95: 298-302.

15. Shishir K, Milton R, Papagiannopoulos K. Simultaneous double video mediastinoscopy and videomediastinotomy-a step forward. European Journal of Cardio-thoracic Surgery 2005; 27: 920-2. [CrossRef]

16. Toloza Em, Harpole L, Detterbeck F, McCrory DC. Invasive staging of non-small cell lung cancer. A Review of the current evidence. Chest 2003; 123: 157S-66S [CrossRef]

17. Van Meerbeeck JP. Staging of non-small cell lung cancer: Consensus, controversies and challenges. Lung cancer 2001; 34: 95S-107. [CrossRef] 